\title{
Detection of lymph node metastasis in lung cancer patients using a one-step nucleic acid amplification assay: a single-centre prospective study
}

\author{
María Escalante Pérez ${ }^{1,2^{*}}$, María Teresa Hermida Romero ${ }^{3}$, Begoña Otero Alén ${ }^{2,3^{*}} \mathbb{0}$, Mónica Álvarez Martínez ${ }^{3}$, \\ Ricardo Fernández Prado ${ }^{4}$, Mercedes de la Torre Bravos ${ }^{4+}$ and Ángel Concha López ${ }^{1,2,3 \dagger}$
}

\begin{abstract}
Background: The use of one-step nucleic acid amplification (OSNA) allows for lymph node (LN) metastasis to be detected rapidly and accurately. We conducted a prospective single-centre clinical trial to evaluate OSNA assay in detecting $L N$ metastasis of lung cancer.

Patients and methods: A total of $705 \mathrm{LNs}$ from 160 patients with clinical stage IA to IVA lung cancer were included in this study. The LNs were divided and submitted to routine histological diagnosis and OSNA assay and the results were compared. We also examined keratin 19 expression of different histological types lung primary tumours.

Results: When the cut-off value was set to 250 copies/ $\mu l$, the concordance rate between the two methods was $96.17 \%$ and the sensitivity $97.14 \%$. Discordant results were observed in 27 LNs of 21 patients. Most of these discordant results were molecular micrometastasis expressing a very low number of copies with negative histology. Most thoracic tumours were positive for keratin 19.

Conclusions: Our data show that the OSNA assay might be a useful and sensitive method to diagnose LN metastasis in lung cancer and could be applied to intraoperative decision-making in personalised lung cancer surgery based on LN status and a more accurate staging of patients.
\end{abstract}

Keywords: Lung cancer, OSNA assay, Metastasis, Intraoperative, LN status, Keratin 19

\section{Background}

Lung cancer is one of the most frequent human cancers and the leading cause of cancer deaths in the world. In the clinical management of the disease, identifying the histological classification by stages is essential for an accurate therapeutic approach for the patients $[1,2]$.

\footnotetext{
*Correspondence: maria.escalante.perez@sergas.es; begona.otero. alen@sergas.es

†Mercedes de la Torre Bravos and Ángel Concha López contributed equally to this work

${ }^{2}$ Molecular Biology Area, Department of Anatomical Pathology, University Hospital Complex A Coruña, As Xubias 84, 15006 A Coruña, Spain

3 Department of Anatomical Pathology, University Hospital Complex A Coruña, As Xubias 84, 15006 A Coruña, Spain

Full list of author information is available at the end of the article
}

Diagnostic methods, such as endobronchial (EBUS) and oesophageal ultrasounds (EUS), fine-needle aspirations, or mediastinoscopies, are carried out to take samples of mediastinal lymph nodes (LNs) to perform the presurgical staging of the patient [3]. In patients with an early pathological stage, once the main tumour has been resected, the regional LNs are studied for the pathological staging that will define the treatment [2]. Traditionally, this step has been performed through microscopic examination of histological sections, the sensitivity of which can be increased by immunohistochemistry (IHC). Currently, the molecular detection of keratin 19 (KRT19) is a routine method in the clinical practice of breast cancer [4]. KRT19 is a type I keratin with a low molecular weight. It is part of the cytoskeleton of numerous 
epithelial cells of different organs, but is not detected in any of the cellular components of the LNs. Furthermore, it is highly expressed in epithelial tumours, so it is an appropriate biomarker for detecting micro- and macrometastasis. The one-step nucleic acid amplification (OSNA) assay is an automated molecular diagnostic assay that analyses the entire LN tissue. The reaction is based on rapid nucleic acid amplification technology, a loop-mediated isothermal amplification (RT-LAMP), to quantify KRT19 mRNA expression [5, 6]. The expression rate of KRT19 mRNA correlates with the size of the metastatic foci. In the last few years, the OSNA assay has been developed as an alternative intraoperative method for detecting of tumour metastasis in breast, gastric, and colorectal cancers $[4,7,8]$. Additionally, the feasibility of OSNA for other malignancies like thyroid, endometrial, head and neck and bronchopulmonary carcinomas is being investigated [9-12]. Only a few reports have been published about the potential of the OSNA assay in nonsmall cell lung cancer (NSCLC) patients [10, 13-15]. In this study we examined 705 LNs of 160 patients with lung cancer by OSNA assay. It represents the biggest cohort of patients and single measured LNs and one of only two reports outside of Japan. Furthermore, this is a singlecentre study, with the subsequent advantage of a strictly standardised protocols and methodology. All LNs were divided to be evaluated by routine histological diagnosis or OSNA assay and the results were compared. We also evaluated the KRT19 expression rate in different types of primary thoracic tumours by IHC and OSNA. The purpose of the project was to test whether the OSNA assay is an accurate, feasible and adequate method for analysis of LN metastasis in lung cancer patients both in intraoperative and definitive pathological diagnoses.

\section{Patients and methods}

\section{Patients and human samples}

This study was conducted as a single-centre clinical performance study between July 2015 and December 2018 . The study was done in compliance with the Declaration of Helsinki. Approval from the Clinical Research Ethics Committee, patients written informed consents custody and sample storage was managed by the Biobank of A Coruña.

A total of 705 LNs from 160 patients with lung cancer and a clinical stage IA to IVA according to the latest WHO classification [16] who underwent pulmonary resection by video-assisted thoracoscopic surgery (VATS) at University Hospital Complex of A Coruña, were included in this study. Patients with prior neo-adjuvant chemotherapy or radiotherapy, recurrent disease, or any previous or synchronous malignancy were excluded from this study. Of the included patients, 15 of them presented intestinal adenomas with low grade dysplasia; and 7 patients had suffered non-infiltrating carcinomas of different types within the 5 years before the start of the study. Furthermore, 9 additional patients with diverse granulomatous diseases were included as negative controls: 5 sarcoidosis, 3 tuberculosis and 1 aspergillosis. Demographic parameters and baseline characteristics of the patients were recorded and are shown in Table 1.

\section{Preparation of LNs}

After removal, LNs with a minimal weight of $0.1 \mathrm{~g}$ and a maximal of $1.2 \mathrm{~g}$ were immediately divided into 4 or 6 blocks depending on their size (4 blocks $\leq 1 \mathrm{~cm} ; 6$ blocks' $1 \mathrm{~cm})$. Non-adjacent blocks were alternatively used for either the histological examination or the OSNA assay as shown in Fig. 1.

\section{Histological examination}

The haematoxylin/eosin (H/E)-stained histological slides from formalin-fixed, paraffin-embedded (FFPE) of LN surgical specimens and dissection were examined by two expert pathologists (THR, AC) blinded to the OSNA results. The pathological staging and histological diagnosis were based on the latest AJCC Cancer Staging Manual of the TNM classification for lung cancer [17], and the WHO Classification of Tumours of the Lung, Pleura, Thymus and Heart [16], respectively, with the aid of immunohistochemical panels. Any discordant results were resolved by consensus.

\section{OSNA assay}

We analysed 705 LNs and 40 primary tumours from 160 patients and 9 granulomatous diseases with the OSNA assay. We used KRT19 mRNA as a marker and the protocol was as previously described [4]. In summary, the resected LNs or primary tumours were homogenised using Lynorhag lysis buffer (Sysmex Corp., Hyogo, Japan). The KRT19 mRNA in each lysate was amplified using a Lynoamp BC gene amplification reagent (Sysmex Corp., Hyogo, Japan), then a 20- $\mu$ l sample of each lysate was subjected to a RT-LAMP reaction. Amplification of KRT19 mRNA was detected by measuring the rise time based on a standard curve using an RD-100i (Sysmex Corp., Hyogo, Japan). The results of the assay were expressed as KRT19 mRNA copy numbers per microliter. The cut-off for micrometastasis was set at 250-5000 copies/ $\mu \mathrm{l}$ and over 5000 copies/ $\mu \mathrm{l}$ was considered macrometastasis; less than 250 copies/ $\mu \mathrm{l}$ was considered negative.

\section{Immunohistochemical analysis}

When discordance results were observed between the OSNA assay and common pathological examination, serial sections from the same tissue blocks were analysed 
Table 1 Baseline characteristics of the patients

\begin{tabular}{|c|c|c|c|c|c|}
\hline Variables & No. & $\%$ & Variables & No. & $\%$ \\
\hline Patients & 160 & & Pathological stage & 160 & \\
\hline Male & 115 & 71.88 & $\mid \mathrm{A} 1$ & 5 & 3.13 \\
\hline Female & 45 & 28.13 & $\mathrm{~A} 2$ & 25 & 15.63 \\
\hline Age (year) & & & IA3 & 20 & 12.50 \\
\hline Mean (range) & $65.07(22-85)$ & & IB & 31 & 19.38 \\
\hline Surgical type of resection & 160 & & $\| \mathrm{A}$ & 11 & 6.88 \\
\hline Bi-lob & 7 & 4.38 & $\| B$ & 39 & 24.38 \\
\hline LID & 22 & 13.75 & $\| I I A$ & 24 & 15.00 \\
\hline LII & 18 & 11.25 & $\| \mathrm{B}$ & 4 & 2.50 \\
\hline LSD & 63 & 39.38 & IVA & 1 & 0.63 \\
\hline LSI & 46 & 28.75 & Dissected lymph nodes & 705 & \\
\hline BPI & 1 & 0.63 & Hilar & 72 & 10.21 \\
\hline LMD & 3 & 1.88 & Interlobar & 52 & 7.38 \\
\hline Histology & 160 & & Paratraqueal & 184 & 26.10 \\
\hline Adenocarcinoma & 94 & 58.75 & Pulmonary ligament & 38 & 5.39 \\
\hline Squamous cell carcinoma & 37 & 23.13 & Peribronchial & 39 & 5.53 \\
\hline Adenosquamous carcinoma & 5 & 3.13 & Subcarinal & 225 & 31.91 \\
\hline Small cell lung carcinoma & 6 & 3.75 & AP window & 75 & 10.64 \\
\hline Large-cell carcinoma & 7 & 4.38 & Other & 20 & 2.84 \\
\hline Carcinoid & 8 & 5.00 & Pathological N status & 160 & \\
\hline Lymphoepithelioma like carcinoma & 1 & 0.63 & $\mathrm{pNO}$ & 118 & 73.75 \\
\hline Carcinoma NOS & 1 & 0.63 & $\mathrm{pN} 1$ & 25 & 15.63 \\
\hline Pleomorphic carcinoma & 1 & 0.63 & $\mathrm{pN} 2$ & 17 & 10.63 \\
\hline
\end{tabular}

by IHC. Specimens were cut into blocks $3.5 \mu \mathrm{m}$ thick. The first section was stained using a mouse monoclonal antibody cocktail reacting with human cytokeratins AE1/ AE3 PCK26 (Anti-Pan Keratin, Ventana Medical Systems, TX, USA). The second section was stained using a mouse monoclonal antibody anti-KRT19 (clone A53-B/ A2.26, Ventana Medical Systems, TX, USA). An immunohistochemistry was performed according to previous protocols using the BenchMark Ventana immunostainer automated method (Ventana Medical Systems, TX, USA). The procedure was as follows: deparaffinisation and rehydration using xylene and concentrated ethylene; heat-induced antigen retrieval; incubation with the primary antibodies; incubation with horseradish peroxidase-conjugated polymers (ultraView Universal DAB Detection Kit, Ventana Medical Systems, TX, USA); chromogenic reaction using $\mathrm{DAB}-\mathrm{H}_{2} \mathrm{O}_{2}$; counterstaining with haematoxylin. Appropriate negative and positive controls were run parallel to the staining procedures. In addition, 160 lung resected primary tumours and 9 granulomatous diseases were also examined for KRT19 IHC expression, one representative sample from each patient.

Expression levels were classified based on an adapted Allred scoring system for quantification of hormonal receptors [18], and ERBB2 testing in breast cancer [19].
It is a semiquantitative system that takes into consideration the proportion of positive cells (scored on a scale of $0-5$ ) and staining intensity (scored on a scale of $0-3$ ). The proportion and intensity were then added to produce a total score range of 0 to 8 . A score of $0-4$ was considered negative, while a score from 5 to 8 was considered positive. Photographs were taken using an Olympus BX50 microscope and DP70 software (Olympus Corporation, Tokyo, Japan). Two different observers performed the evaluations independently. Any discordant results were resolved by consensus.

\section{Statistical analysis}

Descriptive statistics have been used for characterising the clinical and pathological data of the patients in the study. The sample size has been determined mainly based on feasibility. The comparative analysis of the OSNA assay to the histological system was analysed using the $x^{2}$ test model. A unilateral significance level of $0.05 \%$ and a power of $90 \%$ was used to declare a result as statistically significant. The accuracy of the OSNA molecular method with respect to anatomopathological results was analysed by describing the proportion of non-inferiority, the kappa statistic and their respective confidence intervals $(\mathrm{CI})$ of 95\%. 


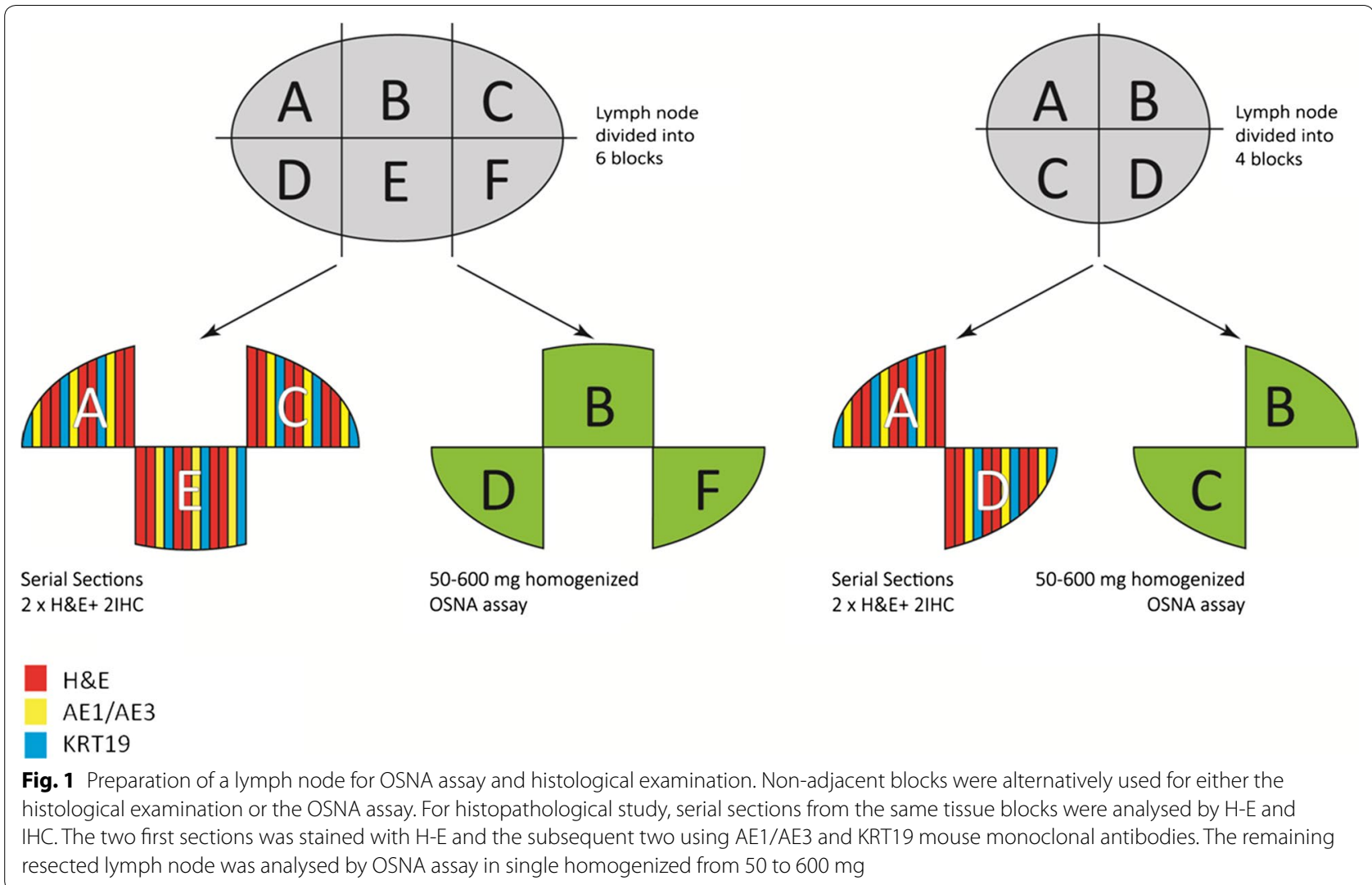

Table 2 LNs results

\begin{tabular}{llll}
\hline OSNA & & H-E/IHQ & \\
\cline { 3 - 4 } & & Positive & Negative \\
\hline++ & Positive & 22 & 4 \\
& Negative & 1 & 678 \\
$++/+$ & Positive & 34 & 26 \\
& Negative & 1 & 644 \\
\hline
\end{tabular}

+ : micrometastasis; ++ : macrometastasis

\section{Results}

\section{Correlation between the OSNA assay and the histological} examination

A total of 705 LNs obtained from 160 patients with lung cancer in different stages were used for concordance analysis with the OSNA assay and the routine histological examination for staging. Of the 705 LNs, 644 were diagnosed by OSNA assay as negative, 34 with -micrometastasis and 26 with -macrometastasis (Tables 2, 3). Two samples with isolated tumour cells (ITCs) were found in our study, intrasinusoidal and in intravascular thromby in lymphatic channel. Both positive by $\mathrm{H}-\mathrm{E}$. We compared the validity (sensitivity and
Table 3 OSNA

\begin{tabular}{lll}
\hline & ++ & + and ++ \\
\hline Concordance (\%) & 99.29 & 96.17 \\
Specificity (\%) & 99.41 & 96.12 \\
Sensitivity (\%) & 95.65 & 97.14 \\
PPV (\%) & 84.62 & 56.67 \\
NPV (\%) & 99.85 & 99.84 \\
\hline
\end{tabular}

specificity) and reliability (positive (PPV) and negative predictive value (NPV)) of the OSNA method versus the gold standard (pathological study: histology and IHC). Accepting only macro-macrometastasis as positive, as established in breast cancer, our results showed a $99.29 \%$ concordance rate with a kappa statistic of 0.894 (95\% CI $80.20-98.60 \%$ ). The sensitivity of the OSNA assay as compared to the pathological examination was $95.65 \%$ (95\% CI 79.01-99.78\%) and specificity was $99.41 \%$ (95\% CI 98.50-99.77\%). PPV and NPV was $84.62 \%$ and $99.85 \%$, respectively.

When the cut-off value was set as $250 \mathrm{copies} / \mu \mathrm{l}$, as reported in previous studies on other organs [4], we obtained a $96.17 \%$ accuracy with a kappa statistic 0.697 
(95\% CI 59.00-80.40\%), 97.14\% sensitivity, $96.12 \%$ specificity; and values of $56.67 \%$ PPV and $99.84 \%$ NPV (Table 3). These results are similar to those obtained in other similar studies [12-15].

Our results showed that with both comparisons the p-value from the non-inferiority test between OSNA and gold standard was $<0.0001$ with a $95 \%$ of CI, i.e. OSNA assay is a method non-inferior to gold standard in the diagnosis of LN metastasis.

\section{Analysis of discordant cases}

We found a high correlation between anatomopathological diagnosis by $\mathrm{H} / \mathrm{E}$ and the results obtained by OSNA assay, however discordant results were observed in 27 LNs (21 patients), less than $5 \%$ of all LNs analysed. Twenty-six lymph nodes were found negative for $\mathrm{H} / \mathrm{E}$ and IHC and positive for OSNA. On the other hand, only one LN was negative by the OSNA assay and diagnosed as metastatic in the histological study. Twenty-two LNs were histologically negative but considered positive for - micrometastasis by the OSNA assay. Most of these cases presented several relatively low mRNA copies (less than 1000 copies). Two of these patients with discordant -micrometastasis (no. 15 and no. 16) also showed -macrometastasis levels of KRT19 in other different LNs by the OSNA assay and were also negative by the pathological examination. Curiously, one of them was diagnosed histologically metastatic in the subsequent pathological study of whole surgical specimen and staged as $\mathrm{pN} 2$ (Table 4).

Of the remaining 4 discordant LNs showing - macrometastasis by the OSNA assay, in three of them we detected very high levels of mRNA copies. However, in all the cases no metastatic deposits were found by conventional methods or IHC for KRT19 and AE1/AE3 to ensure the non-existence of isolated neoplastic cells. Although LNs had some non-epithelial cells expressing AE1/AE3, no KRT19 expression was observed in those cells (Fig. 2).

The only negative LN by OSNA and positive by $\mathrm{H} / \mathrm{E}$ presented a metastatic intranodal focus of $4 \times 5 \mathrm{~mm}$ in size. The size of the -macrometastasis suggested that this discordance could have been due to a sampling bias.

\section{KRT19 expression levels in primary lesions, correlation between OSNA assay and IHC}

We examined KRT19 expression by IHC in all primary tumours of the study and 9 samples of patients with granulomatous diseases. In addition, 40 of these 160 primary tumours and the 9 granulomatous disease samples were examined also by OSNA assay to study the correlation between both diagnostic methods. The expression levels by IHC were quantified by
Table 4 Details of the discordants LNs

\begin{tabular}{|c|c|c|c|c|}
\hline Patient ID & $\begin{array}{l}\text { Number } \\
\text { of discordant } \\
\text { LNs }\end{array}$ & $\begin{array}{l}\text { OSNA } \\
\text { assay } \\
\text { (copies) }\end{array}$ & $\begin{array}{l}\text { Histological } \\
\text { examination }\end{array}$ & $\begin{array}{l}\text { Metastasis } \\
\text { in other } \\
\text { LNs }\end{array}$ \\
\hline \multirow[t]{2}{*}{6} & 2 & 410 & Negative & Negative \\
\hline & & 270 & Negative & \\
\hline 8 & 1 & 1100 & Negative & \\
\hline 12 & 1 & 720 & Negative & Negative \\
\hline 14 & 1 & 270 & Negative & Negative \\
\hline \multirow[t]{3}{*}{15} & 3 & 1600 & Negative & Positive \\
\hline & & 94,000 & Negative & \\
\hline & & 31,000 & Negative & \\
\hline \multirow[t]{2}{*}{16} & 2 & 720 & Negative & Negative \\
\hline & & 170,000 & Negative & \\
\hline 18 & 1 & 950 & Negative & Negative \\
\hline 20 & 1 & 260 & Negative & Negative \\
\hline 26 & 1 & 2200 & Negative & Negative \\
\hline 30 & 1 & 410 & Negative & Negative \\
\hline 39 & 1 & 1400 & Negative & Positive \\
\hline 48 & 1 & 470 & Negative & Negative \\
\hline \multirow[t]{2}{*}{51} & 2 & 530 & Negative & Negative \\
\hline & & 360 & Negative & \\
\hline 61 & 1 & 1100 & Negative & Positive \\
\hline 66 & 1 & 940 & Negative & Negative \\
\hline 67 & 1 & 270 & Negative & Negative \\
\hline 74 & 1 & 410 & Negative & Positive \\
\hline 84 & 1 & 5800 & Negative & Negative \\
\hline \multirow[t]{2}{*}{87} & 2 & 410 & Negative & Negative \\
\hline & & 3400 & Negative & \\
\hline 115 & 1 & 830 & Negative & Negative \\
\hline 94 & 1 & - & Positive & Negative \\
\hline
\end{tabular}

the adapted Allred method scoring system, as previously mentioned. All the lesions of granulomatosis were negative for KRT19 by OSNA and IHC. Regarding primary tumours, we have analysed 19 adenocarcinomas, 13 squamous-cell carcinomas, 2 adeno-squamous carcinomas, 2 large-cell carcinomas, 1 mixed neuroendocrine tumour, 1 lymphoepithelioma-like carcinoma and 2 small-cell carcinomas (Table 5). All tumours were positive by the OSNA assay apart from one small-cell carcinoma. Furthermore, most of them showed high expression levels of KRT19 mRNA except one adenocarcinoma and one epidermoid carcinoma. The expression rate of all histological types apart from small-cell carcinomas was $100 \%$ by IHC and the OSNA assay. The protein expression detected for adenocarcinomas and adeno-squamous carcinomas was the maximum (median score (ms):8); and for the squamous carcinomas it was 7.9. Mixed neuroendocrine tumours and lymphoepithelioma-like carcinomas showed a score of 


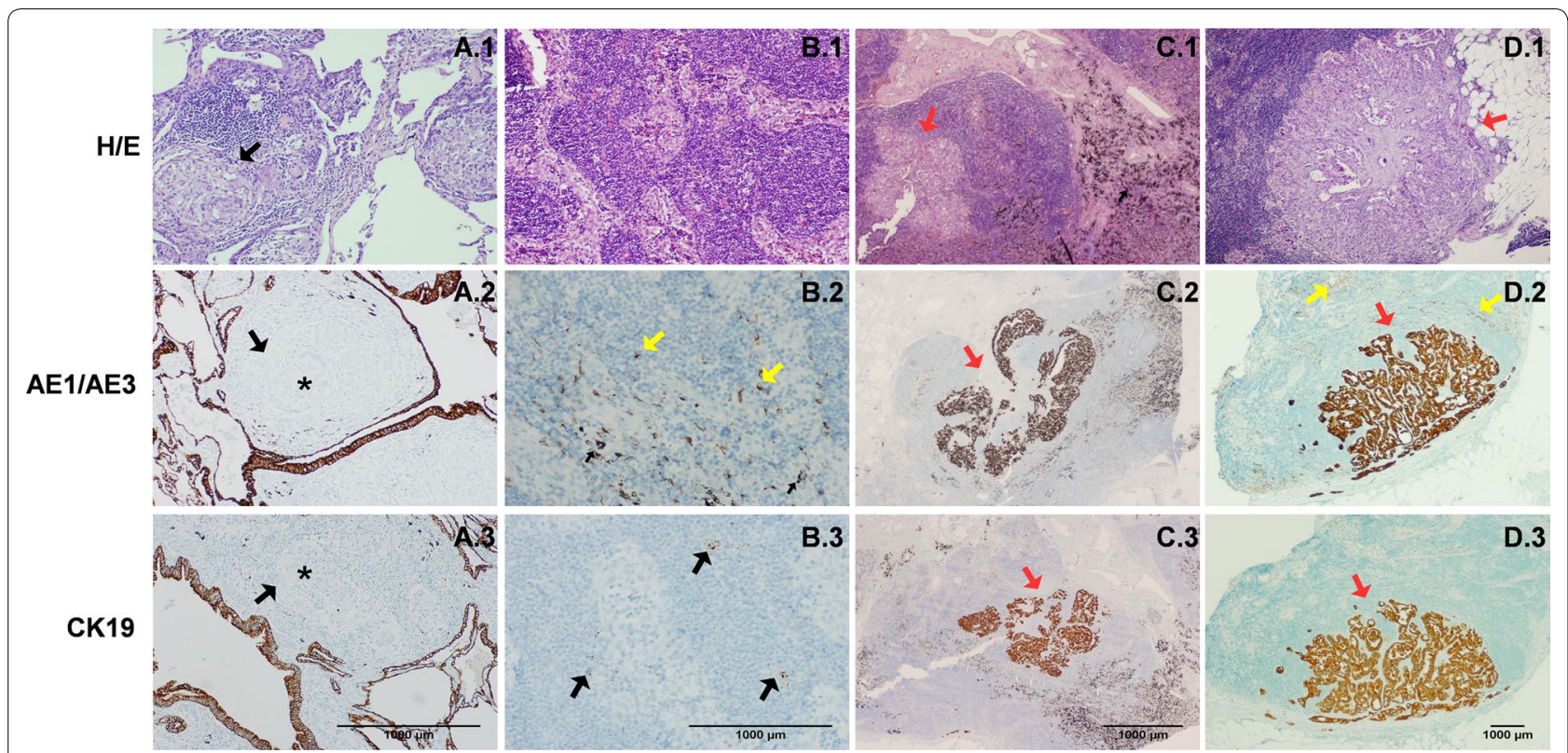

Fig. 2 Haematoxylin/eosin, pan-keratin AE1/AE3 and KRT19 expression in sarcoidosis and lymph node samples. a Sarcoidosis. The epithelial cells (asterisk) of the granulomas (black arrows) are negative for both AE1/AE3 and KRT19 ( $\times 10)$. b Non-metastatic lymph node. The lymph nodes have isolated cells that express AE1/AE3 (accessory cells; yellow arrows), but not KRT19. Anthracotic pigment (black arrows) (x 10). c Micrometastatic lymph node. Lymph node with a deposit of $1.8 \mathrm{~mm}$ of positive neoplastic cells for AE1/AE3 and KRT19 (red arrows) (x4). d Macrometastatic lymph node. Lymph node with expression of AE1/AE3 in accessory cells (yellow arrows) and AE1/AE3 and KRT19 in the tumour cells (macrometastasis of $6 \mathrm{~mm}$; red arrows) $(\times 2)$

\section{Table 5 KRT19 expression levels in the primary tumor}

\begin{tabular}{|c|c|c|c|c|c|c|c|c|}
\hline \multirow[t]{2}{*}{ Histological type } & \multirow{2}{*}{$\begin{array}{l}\text { Total } \\
40\end{array}$} & \multicolumn{3}{|c|}{ KRT19 expression OSNA } & \multicolumn{2}{|c|}{ KRT19 IHQ } & \multicolumn{2}{|c|}{ Expression rate } \\
\hline & & ++ & + & - & + & Median score & IHC (\%) & OSNA (\%) \\
\hline Adenocarcinoma & 19 & 17 & 2 & 0 & 19 & 8 & 100 & 100 \\
\hline Squamous carcinoma & 13 & 12 & 1 & 0 & 13 & 7.9 & 100 & 100 \\
\hline Adenosquamous carcinoma & 2 & 2 & 0 & 0 & 2 & 8 & 100 & 100 \\
\hline Large cell carcinoma & 2 & 2 & 0 & 0 & 2 & 5.5 & 100 & 100 \\
\hline Mixed neuroendocrine tumor & 1 & 1 & 0 & 0 & 1 & 6 & 100 & 100 \\
\hline Lymphoepithelioma-like carcinoma & 1 & 1 & 0 & 0 & 1 & 6 & 100 & 100 \\
\hline Small cell carcinoma & 2 & 1 & 0 & 1 & 1 & 5 & 50 & 50 \\
\hline
\end{tabular}

\section{(See figure on next page.)}

Fig. 3 Haematoxylin/eosin and KRT19 expression in lung primary tumours. a Small cell carcinoma. Only isolated cells are positive for KRT19 (‘1\%; red arrows). $\mathbf{b}$ Large cell carcinoma. Heterogeneous immunostaining with a positive pattern of ${ }^{\prime} 10 \%$ of tumour cells (red arrows). $\mathbf{c}$ Large cell carcinoma. Heterogeneous expression of numerous neoplastic cells with different levels of expression (black and yellow arrows), although obvious in all of them. $\mathbf{d}$ Mixed neuroendocrine carcinoma. Differential expression between the two components of the neoplasm: weak and patchy in the small cell (green arrow) and intense and diffuse in the large cell component (blue arrow). e Lymphoepithelioma-like carcinoma. Neoplastic cells show a faint and heterogeneous pattern (black arrows) although some elements show high expression of KRT19 (yellow arrows). f Pleomorphic carcinoma. Intense immunostaining in the glandular component (green arrow) and heterogeneous pattern of less intensity in the sarcomatoid fraction (blue arrow). g Adenocarcinoma. Heterogeneous but obvious pattern of expression of KRT19 (black and yellow arrows). $\mathbf{h}$ Adenocarcinoma. Intense and diffuse positivity for KRT19 in the whole tumour. i Squamous cell carcinoma. High expression of KRT19 in all tumour cells. Objective magnification $\times 10$ 


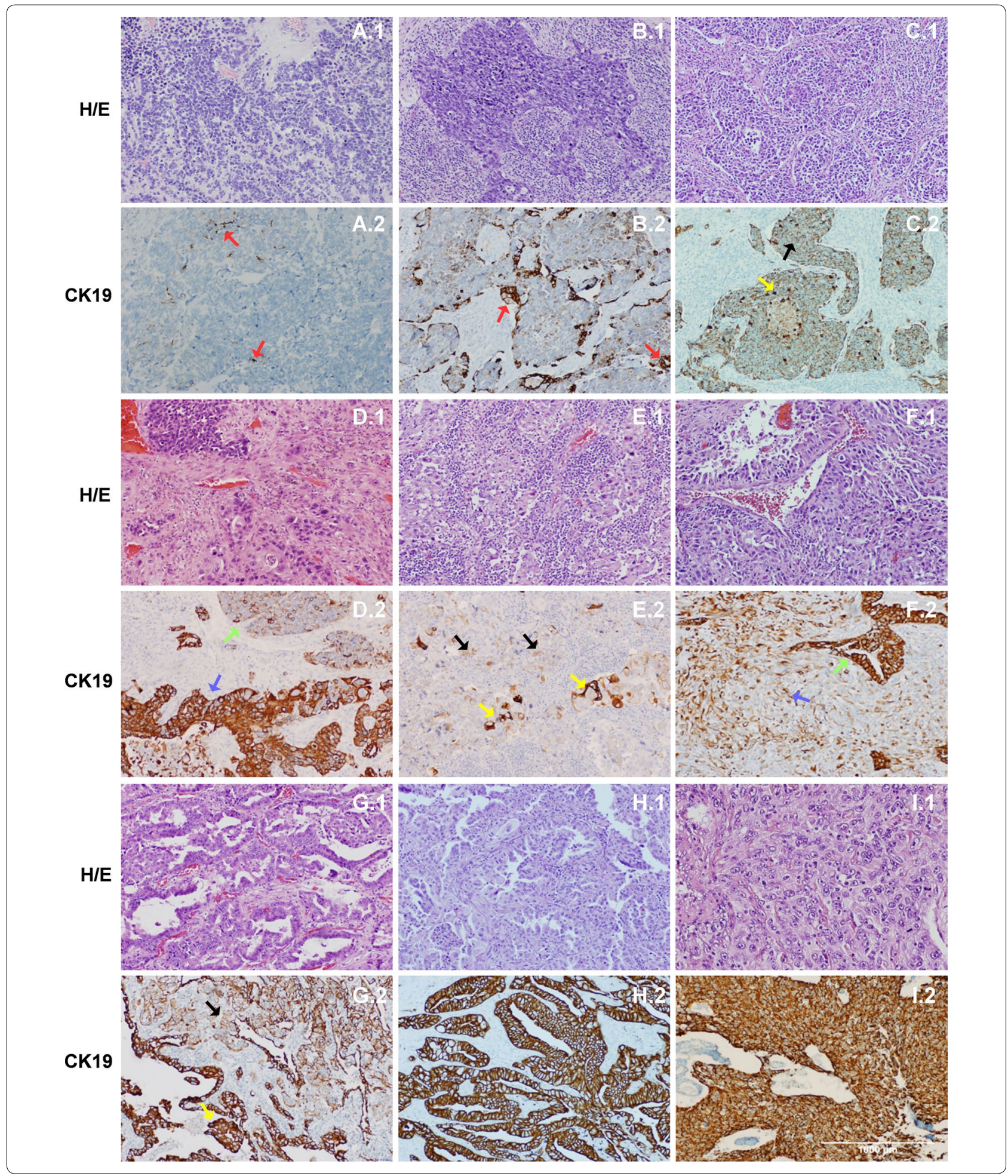

6 (both: 3 of positive cells +3 of staining intensity) by the Allred system. Large-cell carcinomas showed a ms of 5.5 by IHC (more than 33\% of cell expression and high intensity) (Fig. 3).
We also examined 2 small-cell carcinomas. Only one was negative for KRT19 by both expression methods (ms of $4 ; 1+3$, less than $1 \%$ of cell expression and high intensity). By the OSNA assay the positive primary tumour 
expressed high levels of KRT19, while the median score by IHC was 5 .

\section{Discussion}

Lung cancer is a disease with a high mortality. Some of the complexity associated with the pathology is due to its heterogeneous nature. Large-scale sequencing studies have revealed the complex genomic landscape of NSCLC and strong differences between lung adenocarcinomas and lung squamous-cell carcinomas [20]. However, both tumour types have an over 96\% expression of KRT19, a commonly used marker for epithelial tumours [20]. In most pleural and lung tumours, positive rates for expression of KRT19 range from 70 to $100 \%$. In small-cell carcinomas the expression rate is almost $60 \%$ [21-23]. But, the criteria for immunohistochemical scores are not protocolled. Literature shows different evaluation ranges, and the fact is that the positive threshold is not yet properly established for KRT19 in lung cancer. Nevertheless, this biomarker is widely expressed in bronchopulmonary malignancies. Moreover, all LN metastasis from KRT19-positive primary lung tumours express the protein by IHC. Surprisingly, deposits from KRT19 negative primary neoplasms can be positive for KRT19 in LNs too [20]. This fact is commonly observed in breast cancer, where $67 \%$ of KRT19 negative primary tumours show KRT19 positivity in LNs metastasis [24]. Our results in primary lung tumours showed high KRT19 expression by OSNA and $\mathrm{IHC}$, not only in number of positive cells, but also in staining intensity. Only neuroendocrine carcinomas presented lower rates. These data suggest that KRT19 is an accurate biomarker for detecting metastasis in lung malignancies and that, unlike in breast cancer, performing IHC for KRT19 from the primary tumour site prior to OSNA analysis might not be necessary. In contrast, our samples of different granulomatous diseases were negative for KRT19 both by OSNA and pathological examination.

In this context, our present findings in 160 patients demonstrated that the OSNA assay successfully predicts LN metastasis in lung cancer, showing high specificity, concordant rates and NPV by comparison with the gold standard technique. These results are in accordance with the few previous studies in NSCLC that are similar [10, 13-15]. Furthermore, our research includes a larger number of patients and LNs analysed individually in a single-centre study. This fact implies a strictly standardised and normalised protocol for the performance of the whole process with an experienced surgical and diagnostic team in these procedures. However, this premise may have its weaknesses and limitations, so for the next step for validation of the technique in lung cancer, it would be necessary to conduct a multi-centre study in which not all variables and characteristics are controlled, in order to established our results.

Despite our high concordance rate, 27 LNs showed discordant results in 21 patients. Regarding -macrometastasis, 4 LNs were OSNA positive and pathological examination was negative, with two of them belonging to the same patient who underwent an N2 stage with other affected LNs. This case could be due to a sampling bias, as it was the only OSNA negative discordance with a positive histological diagnostic. LN metastasis are usually diagnosed with a postoperative pathological examination of permanent sections. However, with this method, small areas of metastasis between slices may go undetected, as may micro-micrometastasis or ITCs. Single tumour cells or small aggregates of tumour cells can be overlooked among the lymphocytes and sinusoidal histiocytes that could lead to a false-negative assessment [25]. Moreover, only a small part of the node is analysed each time. The great advantage of the OSNA assay is its ability to examine the whole LN as compared with the pathological examination, which scans only several sections. Furthermore, histological examination procedures for LNs are not standardised, and the inter-observer reproducibility of measuring metastatic tumour volume can occur [26]. This could lead to an under-stage pathology and the subsequent inappropriate treatment. Although KRT19 is present in healthy epithelial cells [10], the protocol for LN resection and processing in the laboratory prior to OSNA analysis avoids any potential false positives due to contamination. Likewise, the presence of benign epithelial inclusions is exceptional in mediastinal LNs, as well as its likelihood to cause a false-positive result. The differences and similarities between histopathological procedures and OSNA assay is shown in comparison Table 6 .

The high sensitivity of the OSNA assay also enables detecting of occult - micrometastasis missed by pathological examinations. We detected $22-$ micrometastasis with a negative KRT19-IHC. The significance of these findings is not clear, nor are the implications in treatment decisions. Patients with pathological pN0 or pN1 diseases have heterogeneous outcomes [27-29]. Maybe these occult -micrometastasis are the key to explaining why some of these cases are classified as pN0 or pN1 after surgery, by means of conventional methods, progressing with worse clinical course. In breast cancer there are discrepancies about the presence of these microdeposits and whether they have do or do not have an impact on disease-free survival (DFS) and overall survival (OS) [30-32]. The same conflicting results are shown for lung cancer. Rena et al. [33] showed that LN ITCs and micrometastasis in pathological stage I NSCLC do not affect long term DFS. In contrast, other groups concluded that patients with ITCs 
Table 6 Technical comparison between histological procedures and OSNA assay

\begin{tabular}{|c|c|c|}
\hline & Histological examination & OSNA assay \\
\hline Tumour topography & $\begin{array}{l}\text { Exhaustive study of tissue topography and detection of } \\
\text { extracapsular extension }\end{array}$ & $\begin{array}{l}\text { The assay do not enable the study of tumour topography, } \\
\text { but adjacent lymph node tissue is analysed by comple- } \\
\text { mentary histological procedures }\end{array}$ \\
\hline Morphological study & $\begin{array}{l}\text { Study of metastatic deposits and isolated neoplastic cells. } \\
\text { Minimisation of false positives like benignant epithelial } \\
\text { inclusions (exceptional in mediastinal lymph nodes) }\end{array}$ & $\begin{array}{l}\text { The assay do not enable the study of cellular and histological } \\
\text { lymph node morphology }\end{array}$ \\
\hline Sensibility & Lower limit of detection & $\begin{array}{l}\text { More accuracy than histological procedures. Detection of } \\
\text { occult micrometastasis }\end{array}$ \\
\hline Whole lymph node analysis & $\begin{array}{l}\text { Risk of sample bias. Slow and laborious study of whole } \\
\text { lymph node }\end{array}$ & $\begin{array}{l}\text { Fast, feasible and accurate whole lymph node analysis. Mini- } \\
\text { misation of false negatives }\end{array}$ \\
\hline KRT19 quantification & $\begin{array}{l}\text { Relative quantification of KRT19 expression by digital } \\
\text { pathology }\end{array}$ & $\begin{array}{l}\text { Absolute quantification of KRT19 expression that correlates } \\
\text { with metastatic foci. The assay also allows the possibility of } \\
\text { detecting total tumour load }\end{array}$ \\
\hline Assay rapidity/Workflow & $\begin{array}{l}\text { Fast analysis of a single intraoperative slide (less than } \\
15 \text { min) }\end{array}$ & Fast analysis of the whole lymph node (less than 25 min) \\
\hline Methodology & $\begin{array}{l}\text { Standardised procedures. Immunohistochemical scores } \\
\text { and histological examination not protocolled }\end{array}$ & Normalised and standardised protocols. Unbiased results \\
\hline Cost-effectiveness & Higher cost of time, personnel and resources for diagnostic & Lower cost-effectiveness ratio \\
\hline Remnant sample & $\begin{array}{l}\text { Remnant samples are available for histological and } \\
\text { molecular analysis }\end{array}$ & $\begin{array}{l}\text { Remaining lymph node lysates are available for subsequent } \\
\text { molecular analysis }\end{array}$ \\
\hline
\end{tabular}

or micrometastasis in LNs had higher recurrence rates and worse survival rates in early-stage NSCLC [34, 35]. Therefore, the cut-off point of the KRT19 copy number which is pathologically significant is critical. In this work we used the established parameters for breast cancer [4]. Do we need validation studies for the KRT19 mRNA copy numbers set up as cut-off for negative micro- and - macrometastasis in lung cancer? Or are breast cancer approximations accurate enough values applied to mediastinal LNs? The cut-off level of the OSNA assay used in previous studies in gastric, colorectal and lung cancer was also established at 250 copies/ $\mu \mathrm{l}$, considering that the KRT19 mRNA expression level is similar among the various types of malignancies. However, in head and neck cancer, new cut-off levels of 131 and 300 copies/ $\mu$ l were proposed by different studies $[9,36]$. Head and neck tumours are squamous cell carcinomas and expression of KRT19 is a poor prognostic marker [37]. Most breast, gastric, colorectal, and between the 40 and $60 \%$ of lung malignancies, are adenocarcinomas. However, $20-30 \%$ are epidermoids and, thus, the cut-off point established for lung cancer could depend on the histological type of the tumour. For all these reasons, the limits of detection of the assay in bronchopulmonary malignancies must be established, monitoring the progression of patients with conflicting results, micrometastasis deposits and presence of ITCs. Furthermore, in lung carcinomas with low or no expression of KRT19, such as small cell carcinomas, the inclusion of a second or third marker could minimise false negatives and improve the specificity of the test.
On the other hand, in colorectal cancer, the amount of tumour burdens or total tumour loads detected by OSNA were showed to be an accurate LN pathological staging with potential prognostic implications [38]. Moreover, studies show that OSNA positivity in stage II colon cancer patients who are $\mathrm{pNO}$ by $\mathrm{H} \& \mathrm{E}$ is associated with classical high-risk factors and has a prognostic value, suggesting that OSNA could be detecting patients as understaged by histological techniques [39]. The total tumour burden pooled by RT-LAMP has not yet been analysed in lung cancer, but nevertheless could be a promising approach for future studies.

\section{Conclusions}

Our findings show that the OSNA assay is a fast, feasible and accurate technique. It is a methodology that improves cost-effectiveness, accuracy and management of patients with an adequate clinical practice in pre-staging and pathological diagnosis. Furthermore, it is able to detect macrometastatic foci and small metastatic lesions and ITCs that are not identified by conventional techniques. The clinical and prognostic significance of such findings would also need to be evaluated with prospective studies, including a sufficient number of patients and an adequate follow-up period. The analysis of the whole LN by the OSNA assay could overcome the limitations of sample bias and the histological examination. In addition, the remaining $\mathrm{LN}$ lysate has proved to be adequate for subsequent molecular analysis [40]. In conclusion, this work addresses the validity of the procedure as an 


\section{adequate method for diagnosis of LN metastasis in lung cancer.}

\begin{abstract}
Abbreviations
EBUS: endobronchial ultrasounds; EUS: oesophageal ultrasounds; LN: lymph node; IHC: immunohistochemistry; KRT19: keratin 19; OSNA: one-step nucleic acid amplification; RT-LAMP: loop-mediated isothermal amplification; NSCLC: non-small cell lung cancer; VATS: video-assisted thoracoscopic surgery; $\mathrm{H} / \mathrm{E}$ : haematoxylin/eosin; FFPE: formalin-fixed, paraffin-embedded; Cl: confidence interval; ITCs: isolated tumour cells; PPV: positive predictive value; NPV: negative predictive value; DFS: disease-free survival; OS: overall survival.
\end{abstract}

\section{Acknowledgements}

We thank Isabel Sanjurjo Bermúdez for illustrations, Sonia Pértega Díaz for help on statistical analysis and the Immunohistochemistry area of the CHUAC for technical assistance.

\section{Authors' contributions}

ACL, MTB conceive and planned the experiments and were in charge of overall direction and planning. MEP, MTHR, MAM, BOA carried out the experiments. MEP, BOA, MTB, RFP contributed to sample preparation. MEP and BOA wrote the manuscript with support from ACL. All authors discussed the results and commented on the manuscript. All authors read and approved the final manuscript.

\section{Funding}

EPM, OAB and the Department of Anatomical Pathology (University Hospital Complex A Coruña, A Coruña, Spain) received research funding during the study period from Sysmex Corporation (Hyogo, Japan). The sponsor of the study had no role in the performance of the study, data collection, data interpretation or preparation of the report.

\section{Availability of data and materials}

The datasets analysed during the current study are available from the corresponding authors on reasonable request.

\section{Ethics approval and consent to participate}

The Clinical Research Ethics Committee of A Coruña approved the study. An informed consent for participation in the study was obtained from all patients.

\section{Consents for publication}

An informed consent for participation in the study was obtained from all patients.

\section{Competing interests}

The authors declare that they have no competing interests.

\section{Author details}

${ }^{1}$ Biobank of A Coruña, INIBIC, A Coruña, Spain. ${ }^{2}$ Molecular Biology Area, Department of Anatomical Pathology, University Hospital Complex A Coruña, As Xubias 84, 15006 A Coruña, Spain. ${ }^{3}$ Department of Anatomical Pathology, University Hospital Complex A Coruña, As Xubias 84, 15006 A Coruña, Spain. ${ }^{4}$ Department of Thoracic Surgery, University Hospital Complex A Coruña, A Coruña, Spain.

Received: 4 March 2019 Accepted: 5 July 2019

Published online: 22 July 2019

\section{References}

1. Sobin HL, Gospodarowicz M, Witterkind CH. TNM classification of malignant tumours. 2nd ed. Blackwell: Wiley; 2009.

2. Ettinger DS, Wood DE, Aisner DL, Akerley W, Bauman J, Chirieac LR, et al. Non-small cell lung cancer, version 5.2017, NCCN clinical practice guidelines in oncology. J Natl Compr Canc Netw. 2017;15(4):504-35.

3. Annema JT, van Meerbeeck JP, Rintoul RC, Dooms C, Deschepper E, Dekkers $O M$, et al. Mediastinoscopy vs endosonography for mediastinal nodal staging of lung cancer: a randomized trial. JAMA. 2010;304(20):2245-52.
4. Tamaki Y, Akiyama F, Iwase T, Kaneko T, Tsuda H, Sato K, et al. Molecular detection of lymph node metastasis in breast cancer patients: results of a multicenter trial using the one-step nucleic acid amplification assay. Clin Cancer Res. 2009;15(8):2879-84.

5. Notomi T, Okayama H, Masubuchi H, Yonekawa T, Watanabe K, Amino N, et al. Loop-mediated isothermal amplification of DNA. Nucleic Acids Res. 2000:28(12):e63.

6. Nagamine K, Hase T, Notomi T. Accelerated reaction by loop-mediated isothermal amplification using loop primers. Mol Cell Probes. 2002;16(3):223-9.

7. Guller U, Zettl A, Worni M, Langer I, Cabalzar-Wondberg D, Viehl CT, et al. Molecular investigation of lymph nodes in colon cancer patients using one-step nucleic acid amplification (OSNA): a new road to better staging. Cancer. 2012;118(24):6039-45.

8. Kumagai K, Yamamoto N, Miyashiro I, Tomita Y, Katai H, Kushima R, et al. Multicenter study evaluating the clinical performance of the OSNA assay for the molecular detection of lymph node metastasis in gastric cancer patients. Gastric Cancer. 2014;17(2):273-80.

9. Goda H, Nakashiro Kl, Oka R, Tanaka H, Wakisaka H, Hato N, et al. One-step nucleic acid amplification for detecting lymph node metastasis of head and neck squamous cell carcinoma. Oral Oncol. 2012;48(10):958-63.

10. Inoue M, Hiyama K, Nakabayashi K, Morii E, Minami M, Sawabata N, et al. An accurate and rapid detection of lymph node metastasis in non-small cell lung cancer patients based on one-step nucleic acid amplification assay. Lung Cancer. 2012;78(3):212-8.

11. del Carmen S, Gatius S, Franch-Arcas G, Baena JA, Gonzalez O, Zafon C, et al. Concordance study between one-step nucleic acid amplification and morphologic techniques to detect lymph node metastasis in papillary carcinoma of the thyroid. Hum Pathol. 2016:48:132-41.

12. Lopez-Ruiz ME, Diestro MD, Yebenes L, Berjon A, de la Noval BD, Mendiola $M$, et al. One-step nucleic acid amplification (OSNA) for the detection of sentinel lymph node metastasis in endometrial cancer. Gynecol Oncol. 2016;143(1):54-9.

13. Hayama M, Chida M, Karube Y, Tamura M, Kobayashi S, Oyaizu T, Honma K. One-step nucleic acid amplification for detection of lymph node metastasis in lung cancer. Ann Thorac Cardiovasc Surg. 2014;20:3.

14. Nakagawa K, Asamura H, Tsuta K, Nagai K, Yamada E, Ishii G, et al. The novel one-step nucleic acid amplification (OSNA) assay for the diagnosis of lymph node metastasis in patients with non-small cell lung cancer (NSCLC): results of a multicenter prospective study. Lung Cancer. 2016;97:1-7.

15. Vodicka J, Mukensnabl P, Vejvodova S, Spidlen V, Kulda V, Topolcan O, Pesta M. A more sensitive detection of micrometastasis of NSCLC in lymph nodes using the one-step nucleic acid amplification (OSNA) method. J Surg Oncol. 2018;117(2):163-70.

16. Travis WD, Brambilla EB, Burke AP, Marx A, Nicholson AG. WHO classification of tumours of the lung, pleura, thymus and heart, International Agency for Research on Cancer; 2015. https://doi.org/10.1097/jto.00000 00000000663.

17. Rami-Porta R, Asamura H, Travis WD, Rusch VW. Lung cancer-major changes in the American Joint Committee on Cancer cancer eighth edition staging manual. CA Cancer J Clin. 2017;67(2):138-55.

18. Allred DC, Bustamante MA, Daniel CO, Gaskill HV, Cruz AB. Immunocytochemical analysis of estrogen receptors in human breast carcinomas. Evaluation of 130 cases and review of the literature regarding concordance with biochemical assay and clinical relevance. Arch Surg. 1990;125(1):107-13.

19. Wolff AC, Hammond ME, Hicks DG, Dowsett M, McShane LM, Allison KH, et al. Recommendations for human epidermal growth factor receptor 2 testing in breast cancer: American Society of Clinical Oncology/College of American Pathologists clinical practice guideline update. Arch Pathol Lab Med. 2014:138(2):241-56.

20. Jamal-Hanjani M, Wilson GA, McGranahan N, Birkbak NJ, Watkins TBK, Veeriah S, et al. Tracking the evolution of non-small-cell lung cancer. N Engl J Med. 2017;376(22):2109-21.

21. Said JW, Nash G, Banks-Schlegel S, Sassoon AF, Murakami S, Shintaku IP. Keratin in human lung tumors. Patterns of localization of different-molecular-weight keratin proteins. Am J Pathol. 1983;113(1):27.

22. Chu PG, Weiss LM. Keratin expression in human tissues and neoplasms. Histopathology. 2002:40(5):403-39. 
23. Masai K, Nakagawa K, Yoshida A, Sakurai H, Watanabe S, Asamura H, Tsuta K. Cytokeratin 19 expression in primary thoracic tumors and lymph node metastasis. Lung Cancer. 2014;86(3):318-23.

24. Fujisue M, Nishimura R, Okumura Y, Tashima R, Nishiyama Y, Osako T, et al. Clinical significance of CK19 negative breast cancer. Cancers. 2012;5(1):1.

25. Weaver DL, Krag DN, Manna EA, Ashikaga T, Waters BL, Harlow SP, et al. Detection of occult sentinel lymph node micrometastasis by immunohistochemistry in breast cancer. An NSABP protocol B-32 quality assurance study. Cancer. 2006;107(4):661-7.

26. Turner RR, Weaver DL, Cserni G, Lester SC, Hirsch K, Elashoff DA, et al. Nodal stage classification for breast carcinoma: improving interobserver reproducibility through standardized histologic criteria and image-based training. J Clin Oncol. 2008:26(2):258-63.

27. Saintigny P, Coulon S, Kambouchner M, Ricci S, Martinot E, Danel C, et al. Real-time RT-PCR detection of CK19, CK7 and MUC1 mRNA for diagnosis of lymph node micrometastasis in non small cell lung carcinoma. Int J Cancer. 2005;115(5):777-82.

28. Caldarella A, Crocetti E, Comin CE, Janni A, Pegna AL, Paci E. Prognostic variability among nonsmall cell lung cancer patients with pathologic N1 lymph node involvement. Epidemiological figures with strong clinical implications. Cancer. 2006;107(4):793-8.

29. Kelsey CR, Marks LB, Hollis D, Hubbs JL, Ready NE, D'Amico TA, Boyd JA. Local recurrence after surgery for early stage lung cancer: an 11-year experience with 975 patients. Cancer. 2009;115(22):5218-27.

30. de Boer M, van Deurzen CH, van Dijck JA, Borm GF, van Diest PJ, Adang EM, et al. Micrometastasis or isolated tumor cells and the outcome of breast cancer. N Engl J Med. 2009:361(7):653-63.

31. Gobardhan PD, Elias SG, Madsen EV, van Wely B, van den Wildenberg $F$, Theunissen EB, et al. Prognostic value of lymph node micrometastasis in breast cancer: a multicenter cohort study. Ann Surg Oncol. 2011:18(6):1657-64

32. Weaver DL, Ashikaga T, Krag DN, Skelly JM, Anderson SJ, Harlow SP, et al. Effect of occult metastasis on survival in node-negative breast cancer. $\mathrm{N}$ Engl J Med. 2011;364(5):412-21.

33. Rena O, Carsana L, Cristina S, Papalia E, Massera F, Errico L, et al. Lymph node isolated tumor cells and micrometastasis in pathological stage I non-small cell lung cancer: prognostic significance. Eur J Cardiothorac Surg. 2007:32(6):863-7.

34. Osaki T, Oyama T, Gu CD, Yamashita T, So T, Takenoyama M, et al. Prognostic impact of micrometastatic tumor cells in the lymph nodes and bone marrow of patients with completely resected stage I non-small-cell lung cancer. J Clin Oncol. 2002;20(13):2930-6.

35. Jeong JH, Kim NY, Pyo JS. Prognostic roles of lymph node micrometastasis in non-small cell lung cancer. Pathol Res Pract. 2018;214(2):240-4.

36. Matsuzukat T, Takahashi K, Kawakita D, Kohno N, Nagafuji H, Yamauchi $\mathrm{K}$, et al. Intraoperative molecular assessment for lymph node metastasis in head and neck squamous cell carcinoma using one-step nucleic acid amplification (OSNA) assay. Ann Surg Oncol. 2012;19(12):3865-70.

37. Ernst J, Ikenberg K, Apel B, Schumann DM, Huber G, Studer G, et al. Expression of CK19 is an independent predictor of negative outcome for patients with squamous cell carcinoma of the tongue. Oncotarget. 2016;7(46):76151.

38. Rakislova N, Montironi C, Aldecoa I, Fernandez E, Bombi JA, Jimeno $M$, et al. Lymph node pooling: a feasible and efficient method of lymph node molecular staging in colorectal carcinoma. J Transl Med. 2017;15(1):14.

39. Aldecoa I, Atares B, Tarragona J, Bernet L, Sardon JD, Pereda T, et al. Molecularly determined total tumour load in lymph nodes of stage I-II colon cancer patients correlates with high-risk factors. A multicentre prospective study. Virchows Arch. 2016;469(4):385-94.

40. Martin-Sanchez E, Pernaut-Leza E, Mendaza S, Cordoba A, Vicente-Garcia F, Monreal-Santesteban I, et al. Gene promoter hypermethylation is found in sentinel lymph nodes of breast cancer patients, in samples identified as positive by one-step nucleic acid amplification of cytokeratin 19 mRNA. Virchows Arch. 2016;469(1):51-9.

\section{Publisher's Note}

Springer Nature remains neutral with regard to jurisdictional claims in published maps and institutional affiliations.
Ready to submit your research? Choose BMC and benefit from:

- fast, convenient online submission

- thorough peer review by experienced researchers in your field

- rapid publication on acceptance

- support for research data, including large and complex data types

- gold Open Access which fosters wider collaboration and increased citations

- maximum visibility for your research: over $100 \mathrm{M}$ website views per year

At BMC, research is always in progress.

Learn more biomedcentral.com/submissions 